\title{
Gambaran Pasien yang Menjalani Prosedur Bedah Emergensi di RSUP Prof. Dr. R. D. Kandou Manado Periode Januari - September 2019
}

\author{
Utrecht Suleman, ${ }^{1}$ Angelica M. J. Wagiu, ${ }^{2}$ Stephanus J. Ch. Tangel ${ }^{2}$
}

\author{
${ }^{1}$ Program Studi Pendidikan Dokter Fakultas Kedokteran Universitas Sam Ratulangi Manado \\ ${ }^{2}$ Bagian Ilmu Bedah Fakultas Kedokteran Universitas Sam Ratulangi Manado \\ Email: utrecht2112@gmail.com
}

\begin{abstract}
Emergency surgery is performed to avoid further complications of the disease or to save the patient's life. Albeit, there are lack of data in various health centers in Indonesia regarding the evaluation of emergency surgical patients, This study was aimed to obtain the profile of patients undergoing emergency surgical procedures in the Emergency Department of Surgery at Prof. Dr. R. D. Kandou Hospital Manado from January to September 2019. This was a retrospective and descriptive study using patients' medical records. The results showed that there were 540 patients in this study. Most of the patients were adult age group (18-59 years) as many as 343 patients (63.5\%), males 366 patients (67.8\%), and non-traumatic cases 436 patients $(80.4 \%)$. The most common cases of trauma was epidural hemorrhage as many as 23 patients $(4.3 \%)$ meanwhile the most common non-traumatic cases was chronic kidney disease as many as 122 patients $(22.6 \%)$. According to the type of surgery, CDL insertion and laparotomy were performed on 131 patients each (24.3\%). In conclusion, most patients undergoing emergency surgical procedures were 18-59 years old, males, and non-traumatic cases.
\end{abstract}

Keywords: emergency surgery, traumatic cases, non-traumatic cases

\begin{abstract}
Abstrak: Bedah emergensi dilakukan dalam keadaan sangat darurat untuk menghindari komplikasi lanjut dari proses penyakit atau untuk menyelamatkan jiwa pasien. Data mengenai pasien bedah emergensi di berbagai pusat kesehatan di Indonesia masih sangat kurang. Penelitian ini bertujuan untuk mendapatkan gambaran pasien yang menjalani prosedur bedah emergensi di IGD Bedah RSUP Prof. Dr. R. D. Kandou Manado periode Januari sampai September 2019. Jenis penelitian ialah deskriptif retrospektif, menggunakan data rekam medik pasien. Hasil penelitian menunjukkan bahwa dari 540 pasien, didapatkan pasien terbanyak dari golongan usia dewasa (18-59 tahun) yaitu 343 pasien (63,5\%), jenis kelamin laki-laki 366 pasien $(67,8 \%)$, dan kasus non-trauma 436 pasien $(80,4 \%)$. Kasus trauma terbanyak yaitu epidural hemorrhage pada 23 pasien $(4,3 \%)$ sedangkan kasus non trauma terbanyak chronic kidney disease pada 122 pasien $(22,6 \%)$. Menurut jenis tindakan operasi yang terbanyak ialah insersi CDL dan laparotomy, masing-masing 131 pasien (24,3\%). Simpulan penelitian ini ialah pasien yang menjalani prosedur bedah emergensi terbanyak ialah usia 18-59 tahun, jenis kelamin laki-laki, dan jenis kasus non-trauma.
\end{abstract}

Kata kunci: bedah emergensi, kasus trauma, kasus non-trauma

\section{PENDAHULUAN}

Kondisi gawat darurat merupakan keadaan klinis dimana pasien membutuhkan tindakan medis segera guna penyelamatan nyawa serta pencegahan kecacatan lebih lanjut. ${ }^{1}$ Rumah sakit, lebih khusus IGD
(Instalasi Gawat Darurat), salah satu tujuannya yaitu tercapainya pelayanan kesehatan yang optimal bagi pasien secara cepat dan tepat serta terpadu dalam penanganan tingkat kegawatdaruratan sehingga mampu mencegah risiko kematian dan kecacatan 
(to save life and limb) dengan response time selama lima menit dan waktu definitif tidak lebih dua jam. ${ }^{2}$

Kasus bedah emergensi adalah pembedahan yang dilakukan dalam keadaan sangat darurat untuk menghindari komplikasi lanjut dari proses penyakit atau untuk menyelamatkan jiwa pasien. ${ }^{3}$

Kurangnya data di berbagai pusat kesehatan di Indonesia mengenai gambaran pasien bedah emergensi termasuk di RSUP Prof. Dr. R. D. Kandou mendorong penulis untuk meneliti gambaran pasien yang menjalani prosedur bedah emergensi di IGD Bedah RSUP Prof. Dr. R. D. Kandou Manado periode Januari sampai September 2019.

\section{METODE PENELITIAN}

Penelitian ini dilakukan di Instalasi Rekam Medik dan Instalasi Gawat Darurat Bedah RSUP Prof Dr. R. D. Kandou Manado dengan menggunakan data periode Januari-September 2019 dari pasien yang menjalani prosedur bedah emergensi. Jenis penelitian ialah deskriptif retrospektif dengan menggunakan data rekam medik pasien.

Sampel penelitian ialah seluruh data rekam medik kasus yang pernah di rawat di IGD Bedah RSUP Prof Dr. R. D. Kandou Manado periode Januari-September 2019 yang terdapat di Pusat Rekam Medik RSUP Prof Dr. R. D. Kandou.

Penelitian ini telah mendapat persetujuan dari Komisi Etik Penelitian Kesehatan RSUP Prof. Dr. R. D. Kandou Manado, dengan nomor keterangan layak etik yaitu No. 076/EC/KEPK-KANDOU/XI/2019.

\section{HASIL PENELITIAN}

Hasil penelitian mendapatkan bahwa pasien yang memenuhi kriteria inklusi sebanyak 540 orang. Berdasarkan jenis kelamin, didapatkan laki-laki sebanyak 366 pasien $(67,8 \%)$ dan perempuan sebanyak 174 pasien $(32,2 \%)$.

Tabel 1 memperlihatkan karakteristik pasien berdasarkan usia; yang terbanyak ialah kelompok usia 18-59 tahun yaitu 343 pasien $(63,5 \%)$ dan yang paling sedikit ialah kelompok usia $<18$ tahun yaitu 72 pasien $(13,3 \%)$.

Tabel 1. Karakteristik pasien berdasarkan usia

\begin{tabular}{ccc}
\hline $\begin{array}{c}\text { Usia } \\
\text { tahun) }\end{array}$ & $\begin{array}{c}\text { Jumlah } \\
\text { pasien }\end{array}$ & Persentase \\
\hline$<18$ & 72 & 13,3 \\
$18-59$ & 343 & 63,5 \\
$\geq 60$ & 125 & 23,2 \\
Total & 540 & 100 \\
\hline
\end{tabular}

Tabel 2 memperlihatkan bahwa berdasarkan jenis kasus, didapatkan kasus trauma sebanyak 104 pasien (19,3\%) dan kasus non-trauma sebanyak 436 pasien $(80,7 \%)$.

Tabel 2. Karakteristik pasien berdasarkan kasus trauma dan non trauma

\begin{tabular}{ccc}
\hline $\begin{array}{c}\text { Jenis } \\
\text { kasus }\end{array}$ & $\begin{array}{c}\text { Jumlah } \\
\text { pasien }\end{array}$ & Persentase \\
\hline Trauma & 104 & 19,3 \\
Non-trauma & 436 & 80,7 \\
Total & 540 & 100 \\
\hline
\end{tabular}

Tabel 3 memperlihatkan bahwa berdasarkan diagnosis, didapatkan kasus trauma terbanyak yaitu: epidural hemorrhage (23 pasien/4,3\%), fraktur (21 pasien/3,9\%), dan vulnus ictum (18 pasien/3,3\%). Untuk kasus non-tauma terbanyak yaitu: chronic kidney disease/CKD (122 pasien/22,6\%), appendicitis (112 pasien/20,7\%), dan peritonitis (62 pasien/11,5\%).

Tabel 4 memperlihatkan karakteristik pasien berdasarkan jenis tindakan operasi. Jenis tindakan operasi terbanyak yaitu insersi CDL dan laparotomi masing-masing 131 pasien $(24,3 \%)$. Tindakan yang paling sedikit antara lain insisi drainase, colostomy, anterior resection, laminectomy, Whipple procedure, dan reseksi anastomosis masing-masing sebanyak $1(0,2 \%)$. 
Tabel 3. Karakteristik pasien berdasarkan diagnosis

\begin{tabular}{|c|c|c|c|}
\hline $\begin{array}{c}\text { Jenis } \\
\text { kasus }\end{array}$ & Diagnosis & $\begin{array}{c}\text { Jumlah } \\
\text { pasien }\end{array}$ & Persentase \\
\hline \multirow[t]{15}{*}{ Non trauma } & CKD & 122 & 22,6 \\
\hline & Appendicitis & 112 & 20,7 \\
\hline & Peritonitis & 62 & 11,5 \\
\hline & Obstruksi usus & 51 & 9,4 \\
\hline & Hernia inguinalis & 29 & 5,4 \\
\hline & Pneumothorax & 22 & 4,1 \\
\hline & Efusi pleura & 14 & 2,6 \\
\hline & Congenital Absence & 6 & 1,1 \\
\hline & Acute kidney injury & 5 & 0,9 \\
\hline & Carsinoma thyroid & 5 & 0,9 \\
\hline & Hypocalemia & 4 & 0,7 \\
\hline & Diabetic ulcer & 3 & 0,6 \\
\hline & $\begin{array}{l}\text { Malignant neoplasma of } \\
\text { pancreas }\end{array}$ & 2 & 0,4 \\
\hline & Abcess & 2 & 0,4 \\
\hline & Hydropneumothorax & 1 & 0,2 \\
\hline \multirow[t]{16}{*}{ Trauma } & Epidural hemorrhage & 23 & 4,3 \\
\hline & Fraktur & 21 & 3,9 \\
\hline & Vulnus ictum & 18 & 3,3 \\
\hline & Hemothorax & 11 & 2,0 \\
\hline & Trauma tumpul abdomen & 6 & 1,1 \\
\hline & Vulnus laceratum & 5 & 0,9 \\
\hline & Dislocation & 3 & 0,6 \\
\hline & Ruptur trakea & 2 & 0,4 \\
\hline & Ruptur tendon & 2 & 0,4 \\
\hline & Subdural hemorrhage & 2 & 0,4 \\
\hline & Vulnus penetrans & 2 & 0,4 \\
\hline & Crush injury & 2 & 0,4 \\
\hline & Ruptur arteri & 1 & 0,2 \\
\hline & Ruptur tiroid & 1 & 0,2 \\
\hline & Vulnus sclopectrum & 1 & 0,2 \\
\hline & Total & 540 & 100 \\
\hline
\end{tabular}

Tabel 4. Karakteristik pasien berdasarkan jenis tindakan operasi

\begin{tabular}{lcc}
\hline $\begin{array}{c}\text { Jenis } \\
\text { tindakan operasi }\end{array}$ & $\begin{array}{c}\text { Jumlah } \\
\text { pasien }\end{array}$ & Persentase \\
\hline Insersi CDL & 131 & 24,3 \\
Laparatomi & 131 & 24,3 \\
Apendiktomi & 110 & 20,4 \\
Pasang WSD & 40 & 7,4 \\
Herniotomy & 30 & 5,5 \\
Craniotomy & 27 & 5,0 \\
Debridement & 19 & 3,5 \\
Tracheostomy & 8 & 1,5 \\
CVC & 6 & 1,1 \\
Peritoneal drainase & 6 & 1,1 \\
Eksplorasi & 5 & 0,9 \\
Sigmoidostomy & 5 & 0,9 \\
Pasang IPC & 4 & 0,7 \\
Chest Tube & 3 & 0,5 \\
Reposisi dislokasi & 3 & 0,5
\end{tabular}




\begin{tabular}{lcc} 
Amputasi & 2 & 0,4 \\
Reposisi fraktur & 2 & 0,4 \\
Fasiotomi & 2 & 0,4 \\
Insisi drainase & 1 & 0,2 \\
Colostomy & 1 & 0,2 \\
Laminectomy & 1 & 0,2 \\
Anterior resection & 1 & 0,2 \\
Whipple procedure & 1 & 0,2 \\
Reseksi anastomosis & 1 & 0,2 \\
Total & 540 & 100 \\
\hline
\end{tabular}

\section{BAHASAN}

Tujuan penelitian ini ialah untuk mengetahui gambaran pasien yang menjalani prosedur bedah emergensi. Data penelitian didapatkan dari rekam medik pasien yang menjalani prosedur bedah emergensi di IGD Bedah RSUP Prof. Dr. R. D. Kandou Manado periode JanuariSeptember 2019. Pasien yang menjalani prosedur bedah emergensi berjumlah 540 orang yang termasuk dalam kriteria inklusi dari total 1011 pasien yang menjalani prosedur bedah.

Berdasarkan karakteristik menurut usia pasien, didapatkan yang terbanyak pada golongan dewasa (yaitu 18-59 tahun) berjumlah 343 pasien $(63,5 \%)$, diikuti golongan lansia ( $\geq 60$ tahun) berjumlah 125 pasien $(23,2 \%)$, dan golongan anak ( $<18$ tahun) berjumlah 72 pasien $(13,3 \%)$. Hasil penelitian ini sejalan dengan penelitian yang dilakukan oleh Hasri et $\mathrm{al}^{4}$ yang mendapatkan kelompok usia terbanyak pada pasien bedah emergensi ialah rentang usia 26-50 tahun. Penelitian oleh Kepel et $\mathrm{al}^{5}$ melaporkan bahwa kasus kecelakaan lalu lintas terbanyak didapatkan pada kelompok usia 26-35 tahun yaitu dewasa awal. Hal ini didukung dengan mobilitas dari kelompok usia dewasa awal yang lebih tinggi dibandingkan kelompok usia lainnya. Kelompok usia 26-35 juga merupakan usia produktif dengan intensitas terbanyak di luar rumah. Menurut Riyadani et al, ${ }^{6}$ khususnya untuk kasus trauma kecelakaan didominasi oleh pasien usia dewasa yaitu $56,36 \%$ dari keseluruhan kasus (43.541/ 77.248 kasus) di Indonesia pada tahun 2007.

Berdasarkan karakteristik menurut jenis kelamin, didapatkan hasil yang cukup bermakna yaitu jumlah pasien laki-laki lebih banyak dua kali lipat dari perempuan, yaitu 366 pasien $(67,8 \%)$ laki-laki, dan 174 pasien $(32,2 \%)$ perempuan. Hasil penelitian yang dilakukan oleh Marin et al mendapatkan bahwa trauma kepala sebagian besar terjadi pada laki-laki yaitu sebesar 53,92\% (301.574/559.294 kasus) di Amerika pada tahun 2010. ${ }^{7}$ Di Indonesia kasus trauma kecelakaan didapatkan lebih banyak pada laki-laki yaitu 59,16\% dari keseluruhan kasus (45.707/77.248 kasus) pada tahun $2007 .^{6}$

Berdasarkan karakteristik menurut jenis kasus, didapatkan hasil yang cukup bermakna, yaitu jumlah kasus non trauma lebih banyak empat kali lipat dari kasus trauma, yaitu 436 pasien $(80,4 \%)$ vs 106 pasien $(19,6 \%)$ trauma. Menurut penelitian yang dilakukan Takaendengan et al, ${ }^{8}$ kasus non trauma lebih banyak dijumpai daripada kasus trauma di IGD RSUP Prof. Dr. R. D. Kandou Manado. Di Asia sendiri kasus trauma cenderung lebih banyak daripada kasus non trauma seperti trauma kepala dan cedera otot dan tercatat sebanyak 17.007 pasien trauma di Wonju Severance Christian Hospital di Korea periode Januari 2010 sampai Desember 2012. ${ }^{9}$ Namun di Jepang terdapat angka kejadian kasus non trauma tercatat lebih banyak yaitu berkisar 40-60\% dari keseluruhan kasus kegawatdaruratan dalam periode $1965-2008 .^{10}$

Berdasarkan karakteristik menurut diagnosis, didapatkan jumlah kasus trauma terbanyak yaitu epidural hemorrhage 23 pasien $(4,3 \%)$, fraktur 21 pasien $(3,9 \%)$, dan vulnus ictum 18 pasien $(3,3 \%)$. Pada 
kasus non trauma yang terbanyak yaitu CKD 122 pasien (22,6\%), appendicitis 112 pasien $(20,7 \%)$, dan peritonitis 62 pasien $(11,5 \%)$. Cedera kepala paling sering terjadi pada pengendara sepeda motor. Pada cedera kepala, yang paling ditakuti ialah terjadinya pembengkakan pada otak setelah terkena trauma. ${ }^{11} \mathrm{Di}$ Korea dari 4.673 pasien didapatkan kasus trauma yang terbanyak yaitu trauma kepala sebanyak $1286(27,5 \%)$ dan cedera otot sebanyak $1795(38,4 \%){ }^{9}$ Saat ini banyak studi menunjukkan bahwa prevalensi CKD meningkat di berbagai wilayah di seluruh dunia. Prevalensi CKD derajat II sampai V terus meningkat sejak tahun 1988 sejalan dengan peningkatan prevalensi penyakit diabetes dan hipertensi yang juga merupakan penyebab CKD. ${ }^{12}$

Berdasarkan karakteristik menurut jenis tindakan operasi, didapatkan jumlah jenis tindakan operasi sedikit berbeda dengan diagnosis karena adanya diagnosis yang memiliki tindakan variatif. Jumlah tindakan operasi terbanyak yaitu insersi CDL dan laparotomi masing-masing sebanyak $131(24,3 \%)$, selanjutnya apendiktomi sebanyak $110(20,4 \%)$, pasang WSD sebanyak $40(7,4 \%)$, dan yang paling sedikit ialah insisi drainase, colostomy, anterior resection, laminectomy, Whipple procedure, dan reseksi anastomosis masingmasing sebanyak 1 tindakan $(0,2 \%)$.

\section{SIMPULAN}

Gambaran pasien yang menjalani prosedur bedah emergensi di RSUP Prof. Dr. R. D. Kandou periode Januari-September 2019 ialah yang terbanyak pada jenis kelamin laki-laki, golongan usia 18-59 tahun, dan jenis kasus non trauma.

Diharapkan hasil penelitian ini dapat menjadi tolok ukur dalam pelayanan dan penanganan medis khususnya bedah emergensi.

\section{Konflik Kepentingan}

Penulis menyatakan tidak terdapat konflik kepentingan dalam studi ini.

\section{DAFTAR PUSTAKA}

1. Undang-Undang Republik Indonesia No. 44 Tahun 2009 tentang Rumah Sakit.

2. Basoeki AP, Koeshartono, Rahardjo E, Wirjoatmodjo. Penanggulangan Penderita Gawat Darurat Anestesiologi \& Reanimasi. Surabaya: Fakultas Kedokteran Universitas Airlangga, 2008.

3. Brown CVR, Inaba K, Martin MJ, Salim A, editors. Emergency General Surgery: A Practical Approach. USA: Springer International Publishing, 2019.

4. Hasri ET, Hartriyanti Y, Haryanti F. Praktik keselamatan pasien bedah di rumah sakit daerah. Jurnal Manajemen Pelayanan Kesehatan. 2012;4:196-202.

5. Kepel FR, Mallo JF, Tomuka D. Pola luka pada kasus kecelakaan lalu lintas di Bagian Ilmu Kedokteran Forensik dan Medikolegal RSUP Prof. Dr. R. D. Kandou Manado periode Tahun 2017. Jurnal Biomedik. 2019;11(1):23-8.

6. Riyadina W, Suhardi, Permana M. Pola dan determinan sosiodemografi cedera akibat kecelakaan lalu lintas di Indonesia. MKI. 2009;59;464-72.

7. Marin JR, Weaver MD, Yealy DM, Mannix RC. Trends in visits for traumatic brain injury to emergency departments in the United States. JAMA. 2014;311(18):1917-9.

8. Takaendengan DT, Wowiling PAV, Wagiu AMJ. Profil 10 besar kasus di Instalasi Gawat Darurat Bedah RSUP Prof. R. D. Kandou periode Januari-Desember 2015. e-CliniC. 2016;4(2).

9. Chun BS, Il HP, Joong HO, Keum SB, Kang HL, Eunbi L. Epidemiology of trauma patients and analysis of 268 mortality cases: trends of a single center in Korea. Yonsei Med J. 2015;56(1):220-6.

10. Hori S. Emergency medicine in Japan. Keio J Med. 2010;59(4):131-9.

11. Kristanto E, Mallo JF, Yudhistira A. Cedera akibat kecelakaan lalu lintas di Kota Manado. Jurnal Biomedik. 2009;1(3): 180-4.

12. Aisara S, Azmi S, Yanni M. Gambaran klinis penderita penyakit ginjal kronik yang menjalani hemodialisis di RSUP Dr. M. Djamil Padang. Jurnal Kesehatan Andalas. 2018;7(1):42-50. 